\title{
O PNLD E OS GUIAS DOS LIVROS DIDÁTICOS DE CIÊNCIAS (1999 - 2014): UMA ANÁLISE POSSÍVEL
}

\author{
Vilmarise Bobato Gramowski* \\ Nadir Castilho Delizoicov** \\ Sylvia Regina Pedrosa Maestrelli***
}

RESUMO: Este trabalho propõe-se a uma análise dos Guias do Livro Didático (GLD) de Ciências para os anos finais do ensino fundamental. O objetivo é apresentar dados relativos às orientações contidas nos GLDs do Programa Nacional do Livro Didático (PNLD), tendo como foco a fragmentação dos conteúdos presentes nas obras. Da análise realizada nos GLDs foi possível observar que, apesar de os documentos oficiais apontarem para um ensino de Ciências que articule conhecimentos das diferentes áreas, o PNLD segue aprovando, em sua maioria, coleções que apresentam conteúdos organizados de modo fragmentado, limitando, dessa maneira, as opções dos professores para escolha de livros com estrutura diferenciada da tradicional.

Palavras-chave: Guias do Livro Didático. PNLD. Ensino de Ciências.

\section{EL PNLD Y LOS GUÍAS DE LOS LIBROS DIDÁTICOS DE LAS CIENCIAS (1999-2014): UN ANÁLISIS POSIBLE}

RESUMEN: Este trabajo se propone a un análisis de los Guias del Libro Didáctico (GDL) de las Ciencias para los años finales de la primaria. El objetivo es presentar datos relativos a las orientaciones en los GLD del Programa Nacional del Libro Didáctico (PNLD), con foco en la fragmentación de los contenidos presentes en las obras. Del análisis realizado en los GLD fue posible observar que, pese que los documentos oficiales apunten para una enseñanza de las Ciencias que articule conocimientos de las diferentes áreas, el PNLD sigue aprobando, en su mayoría, colecciones que presentan contenidos organizados de modo fragmentado, limitando, así, las opciones de los profesores para elección de libros con estructura diferenciada de la tradicional.

Palabras clave: Guías del Libro Didáctico. PNLD. Enseñanza de las Ciencias.
*Universidade Federal de Santa Catarina (UFSC). Florianópolis, SC - Brasil. Mestre em Educação Científica e Tecnológica pela Universidade Federal de Santa Catarina (UFSC).

Doutoranda no Programa de

Pós Graduação em Educação Científica e Tecnológica (UFSC).

E-mail: < vilmarise.bg@gmail.com>.

**Universidade Comunitária da

Região de Chapecó (Unochapecó) Chapecó, SC - Brasil. Doutora em Educação pela Universidade Federal de Santa Catarina (UFSC).

Professora do Centro de Ciências Humanas e Jurídicas da Unochapecó. Professora colaboradora do Programa de Pós Graduação em Educação Científica e Tecnológica da UFSC. E-mail: < ridanc.nadir@gmail.com>

*** Universidade Federal de Santa Catarina, (UFSC). Florianópolis, SC - Brasil. Doutora em Ciências pela Universidade de São Paulo (USP).

Professora do Programa de Pós Graduação em Educação

Científica e Tecnológica (UFSC). Coordenadora do Núcleo de Estudos em Ensino de Genética, Biologia e Ciências (NUEG-UFSC).

E-mail: < sylviarpm@gmail.com>.

\section{PNLD AND SCIENCES TEXTBOOKS' GUIDES (1999-2014): A POSSIBLE ANALYSIS}

ABSTRACT: This study discusses science textbooks for the final years of elementary school. The purpose is to present data related to the orientations found in Textbook Guides in the National Textbook Program (PNLD). The study focuses on the fragmentation of the content found in textbooks. An analysis of the Textbook Guides indicated that although the official documents call for a science education that articulates various fields of knowledge, the PNLD continues to 
Vilmarise Bobato Gramowski|Nadir Casti1ho Delizoicov|Sylvia Regina Pedrosa Maestre11i

approve mostly textbook collections that present content in a fragmented manner. With this, teachers have limited options to choose books that are organized differently than the traditional, fragmented, way.

Keywords: Textbook Guides. PNLD. Science education. 


\section{INTRODUÇÃO}

A distribuição de Livros Didáticos (LDs) para professores e alunos que frequentam escolas públicas brasileiras é realizada pelo Governo Federal desde 1938 (HÖFLING, 2000). Com a criação do Programa Nacional do Livro Didático (PNLD), na década de 1990, essa distribuição passou a ser uma política pública de Estado e não mais de governo ${ }^{1}$.

O PNLD trouxe algumas alterações em relação a procedimentos anteriores, como: a abolição do livro descartável ${ }^{2}$ e o aperfeiçoamento das especificações técnicas para a produção de LD, visando maior durabilidade e possibilitando a implantação de bancos de LDs. Além disso, o PNLD assumiu o controle do processo decisório sobre a distribuição dos LDs pela Fundação de Assistência ao Estudante (FAE), não havendo mais a participação dos estados e garantindo o critério de escolha do livro pelos professores (BRASIL, 2013a).

Apesar de estar assegurado o acesso aos LD, a qualidade das informações neles contidas, que há anos vinha sendo questionada em trabalhos acadêmicos (AMARAL;MEGID NETO, 1997;FERREIRA; SOARES, 2008; FRACALANZA; MEGID NETO, 2006;), tornou-se uma preocupação para o Ministério da Educação e Cultura (MEC). Assim, a partir de 1994, o MEC implementou medidas para avaliar, de maneira contínua e sistemática, os LDs submetidos à avaliação pelas editoras (LEÃO; MEGID NETO, 2006). O processo de avaliação segue etapas com cronograma definido, iniciando com a publicação, pelo MEC, no Diário Oficial da União, dos editais que estabelecem as regras e o prazo para que editoras brasileiras inscrevam as coleções que desejam ver avaliadas e adquiridas para serem distribuídas às escolas públicas (BRASIL, 2014).

Na sequência, é realizada a etapa de triagem ou avaliação prévia das obras inscritas, por intermédio do Instituto de Pesquisas Tecnológicas do Estado de São Paulo (IPT), a fim de verificar se elas se enquadram nas características técnicas e físicas exigidas no edital. Na etapa seguinte, as coleções que passaram pelo crivo do IPT são encaminhadas para avaliação pedagógica, que consiste na "análise ampla e criteriosa dos aspectos didático-pedagógicos e metodológicos das obras" (BRASIL, 2014), coordenada pela Secretaria de Educação Básica (SEB/MEC).

Essa avaliação é realizada por especialistas das diferentes áreas do conhecimento, oriundos de Instituições de Ensino Superior (IES) e definidos pela própria SEB/MEC, tendo como referência de análise os critérios divulgados pelo edital de inscrição (BRASIL, 2014). Professores da Educação Básica também podem ser convidados a compor a equipe de avaliadores das coleções.

Os documentos resultantes dos estudos e das avaliações realizadas pelas comissões de professores e pesquisadores passaram a ser denominados pelo próprio MEC de Guias de Livros Didáticos (GLDs). A edição desses documentos é realizada pelo MEC, pela SEB e pelo Fundo Nacional para o Desenvolvimento da Educação (FNDE), sendo os primeiros editados em 1999, abrangendo da $5^{a}$ a $8^{a}$ séries (LEÃO; MEGID NETO, 2006). O principal objetivo desses guias é orientar e dar subsídios aos professores para a escolha dos livros didáticos.

Os GLDs do PNLD constituíram objeto de pesquisa de um trabalho de mestrado (GRAMOWSKI, 2014). Este artigo consiste em um recorte dessa 
investigação, com o objetivo de apresentar dados relativos às orientações contidas nos GLDs do PNLD no que se refere à fragmentação dos conteúdos presentes nos livros didáticos. A preocupação com a fragmentação dos conteúdos presentes nos livros didáticos decorre do seguinte fato, nos documentos oficiais que regulamentam o Ensino de Ciências, como: a Lei de Diretrizes e Bases da Educação Nacional (LDB) (BRASIL, 1996), as Diretrizes Curriculares Nacionais (DCN) (BRASIL, 2010a) e os Parâmetros Curriculares Nacionais ${ }^{3}$ (PCN) (BRASIL, 1998a), há a recomendação para a não fragmentação de conteúdos no processo ensino aprendizagem. Essa preocupação se justifica, ainda, devido à disciplina de Ciências englobar conteúdos que se referem a várias áreas do conhecimento, como Biologia, Química, Física e Geociências. Porém, esses conhecimentos são organizados, particularmente, nos anos finais do Ensino Fundamental, de modo fragmentado ${ }^{4}$, ou seja, seguem a divisão dos conteúdos das disciplinas acadêmicas de referência.

Como a maioria dos LDs aprovados pelo PNLD apresenta conteúdos fragmentados e essa característica se mantém ao longo do tempo, pode-se dizer que, no processo de avaliação das obras, a discussão sobre a fragmentação dos conteúdos não está presente. Há, assim, a necessidade de uma análise aprofundada sobre essa característica dos LDs, pouco presente nos GLDs, e ainda sobre as opções de livros didáticos com conteúdos organizados de diferentes formas o que poderia contribuir para a não padronização de conteúdos fragmentados no Ensino de Ciências. Tais questões são importantes também no processo de formação inicial e/ou continuada dos professores.

A partir da LDB (BRASIL, 1996), que tem como objetivo maior, para o ensino fundamental, a formação básica para a cidadania, estabeleceram-se os PCNs e as Propostas Curriculares dos estados. Dessa forma, considera-se que esses documentos foram elaborados como produtos das mentes de legisladores e dirigentes de ensino subsidiados por professores e pesquisadores da área de ciências, materializando políticas públicas e propostas da comunidade científica para nortear o ensino das ciências nas escolas (MACEDO, 2001). É importante observar como a questão da fragmentação de conteúdos aparece nesses textos, conforme é apresentado na sequência.

As Diretrizes Curriculares Nacionais se referem à organização dos conteúdos nas disciplinas, observando que se deve superar o caráter fragmentado das áreas, superando o isolamento e a compartimentalização de conteúdos rígidos e tornando os conhecimentos mais significativos para os educandos (BRASIL, 2010a). Já a LDB:

[...] reforça a necessidade de se propiciar a todos a formação básica comum, o que pressupõe a formulação de um conjunto de diretrizes capaz de nortear os currículos e seus conteúdos mínimos, incumbência que, nos termos do art. $9^{\circ}$, inciso IV, é remetida para a União. Para dar conta desse amplo objetivo, a LDB consolida a organização curricular de modo a conferir uma maior flexibilidade no trato dos componentes curriculares, reafirmando desse modo o princípio da base nacional comum (Parâmetros Curriculares Nacionais), a ser complementada por uma parte diversificada em cada sistema de ensino e escola na prática, repetindo o art. 210 da Constituição Federal. (BRASIL, 1996, p. 14). 
Os PCNs referem-se à fragmentação dos conteúdos de Ciências de sexto ao $9^{\circ}$ ano, advertindo que:

[...] persiste uma tendência que os aborda [os conteúdos] de modo estanque nas disciplinas científicas, tais como se consagraram há mais de um século, e de forma caricatural. Apresentase separadamente Geologia, dentro de água, ar e solo; Zoologia e Botânica, como sendo classificação dos seres vivos; Anatomia e Fisiologia humana, como sendo todo o corpo humano; Física, como fórmulas, e Química, como o modelo atômico-molecular e a tabela periódica. As interações entre os fenômenos, e destes com diferentes aspectos da cultura, no momento atual ou no passado, estudadas recentemente com maior ênfase nas Ciências Naturais, estão ausentes. [...] A compreensão do que é Ciência por meio desta perspectiva enciclopédica, livresca e fragmentada não reflete sua natureza dinâmica, articulada, histórica e não neutra, conforme é colocada atualmente. (BRASIL, 1998a, p. 27).

Diante das orientações e concepções apresentadas nos documentos oficiais, nota-se uma preocupação referente à necessidade de abandonar a proposta fragmentada em direção a uma articulação entre os diversos conhecimentos das diferentes áreas da Ciência para o melhor entendimento dos fenômenos, visto que essa disciplina:

[...] nasceu com o intuito de envolver os vários conteúdos das ciências em uma única disciplina, integrando as diversas áreas das ciências naturais que anteriormente eram conduzidas, separadamente, nas áreas de Química, Física, Biologia e Geociências. (MAGALHÃES JÚNIOR; PIETROCOLA, 2010, p. 175).

Desse modo, a ideia de contextualização dos conteúdos, participação dos alunos, valorização de seus conhecimentos prévios e de seu cotidiano, atrelada a um ensino de Ciências visto como um processo que articula os conhecimentos das diferentes áreas científicas, é uma recomendação presente em todos os documentos verificados. Como esses documentos são referências para o ensino de Ciências, além de orientarem a prática dos professores e a elaboração de planos de ensino nas escolas, eles podem ser utilizados, também, como parâmetros para o desenvolvimento de materiais didáticos bem como a avaliação dos mesmos.

\section{ENCAMINHAMENTOS METODOLÓGICOS}

Neste artigo apresentamos dados decorrentes da análise dos GLD editados em cada um dos processos do PNLD no período de 1999 a 2014, para a disciplina de Ciências dos anos finais do Ensino Fundamental. Trata-se de pesquisa de natureza qualitativa com análise documental (BARDIN, 2009) que buscou sintetizar informações presentes nos documentos e dar um tratamento analítico para os dados obtidos. A análise foi direcionada pelos seguintes parâmetros:

a) a composição das comissões avaliadoras: considerou-se o número de avaliadores em cada um dos processos do PNLD e a permanência ou não destes nos processos subsequentes;

b) os critérios utilizados para a avaliação dos livros didáticos, presentes no 
GLD: foram consideradas as fichas de avaliação que são preenchidas pelos avaliadores, buscando identificar se algum dos critérios referia-se à fragmentação dos conteúdos;

c) as características mais ressaltadas nos textos introdutórios de cada GLD: para tanto, foi realizada a leitura dos textos introdutórios de todos os GLDs, ou seja, de cada processo do PNLD, com a finalidade de verificar se havia algum comentário ou orientação ao professor com relação à identificação da fragmentação dos conteúdos nos livros didáticos de Ciências;

d) as resenhas das coleções com foco na fragmentação dos conteúdos: realizou-se a leitura das resenhas de cada um dos livros didáticos aprovados, em cada PNLD, visando identificar se havia alguma observação quanto à organização e a ausência, ou não, da fragmentação dos conteúdos.

\section{OS GUIAS DO LIVRO DIDÁTICO DE CIÊNCIAS}

Desde o primeiro processo de avaliação de LD de Ciências para os anos finais do Ensino Fundamental, em 1999, seguiram-se outros cinco processos, com frequência trienal, nos anos de 2002, 2005, 2008, 2011 e 2014, e para cada um deles, um GLD foi publicado.

O GLD apresenta a estrutura de cada coleção aprovada, as principais informações sobre cada uma delas, os nomes da equipe responsável pela avaliação e, de forma detalhada, os critérios de avaliação das coleções ${ }^{5}$. Em cada um dos processos do PNLD, o número de avaliadores, a coordenação, as concepções sobre ensino de Ciências e a apresentação dos GLDs sofreram modificações. Avaliamos como positiva a renovação da equipe, pois pode inserir novas ideias, contribuições e discussões relevantes para o processo. No entanto, pode, também, comprometer a qualidade da avaliação, como consideram Fracalanza e Megid Neto (2006, p. 12), ao abandonar "os aspectos mais peculiares do ensino de Ciências, que fazem eco nas Propostas Curriculares Nacionais e nas pesquisas acadêmicas”.

Um dos aspectos apontados por esses autores pode ser observado nas coleções aprovadas e recomendadas, nas quais há o predomínio de uma divisão de conteúdos que corresponde às disciplinas acadêmicas de referência, o que não está de acordo ao recomendado nos documentos oficiais e nas atuais pesquisas em ensino de Ciências. A orientação é trabalhar a disciplina de Ciências explorando sua natureza dinâmica, de maneira a integrar os conhecimentos das diferentes áreas para analisar os fenômenos do cotidiano.

A partir do exame dos GLDs de todos os processos de avaliação do PNLD, no período de 1999 a 2014, observou-se que: 44 coleções foram aprovadas, sendo que algumas delas já o foram em mais de um processo do PNLD; 39 apresentam os conteúdos de maneira tradicional, entendida como conteúdos fragmentados de acordo com as áreas acadêmicas de referência; cinco coleções possuem uma estrutura diferenciada dos conteúdos, ou seja, de forma a articular os conhecimentos de Geociências, Biologia, Química e Física em todos os volumes da coleção referentes aos anos finais do Ensino Fundamental.

O estudo realizado mostrou que, com exceção de cinco coleções de livros didáticos de Ciências que apresentam estrutura diferenciada, as outras não estão organizadas segundo orientações dos PCNs e dos demais documentos oficiais. 
O PNLD de Ciências para os anos finais do Ensino Fundamental ocorreu em 1999, portanto, após a promulgação da LDB de 1996 e da divulgação dos PCN em 1998 e, também, depois da reestruturação das propostas curriculares nos estados brasileiros. Portanto, era de se supor que os critérios de avaliação propostos pelo PNLD refletissem as perspectivas das orientações dos documentos oficiais para o ensino de Ciências.

\section{O PNLD E 0 GLD NO PERÍODO DE 1999 A 2014}

No PNLD de 1999, a comissão de avaliadores da disciplina de Ciências foi composta por 30 professores especialistas de universidades brasileira e professores que atuavam no Ensino Fundamental, coordenados por um professor ligado a uma universidade. Nesse PNLD, os critérios de avaliação das coleções resultaram de debates:

[...] em reuniões e seminários que contaram com a presença de autores e editores e de suas entidades representativas, Conselho Nacional dos Secretários de Educação - CONSED, União Nacional dos Dirigentes Municipais de Educação - UNDIME e professores especialistas. (BRASIL, 2001, p. 23).

Os critérios foram então formulados com base na experiência acumulada nas avaliações anteriores de livros didáticos para os anos iniciais do Ensino Fundamental, já que o primeiro PNLD - Ciências para os anos iniciais foi realizado em 1994 (LEÃO; MEGID NETO, 2006). Ao consultar o site do FNDE e outras fontes do MEC não encontramos reuniões dessa natureza para os processos do PNLD que se seguiram até 2014.

Segundo o GLD 1999, os critérios de avaliação constituíram um primeiro consenso e seguiriam em aperfeiçoamento para as avaliações subsequentes (BRASIL, 1998b). Nas avaliações posteriores, os critérios, que se dividiam em eliminatórios e classificatórios, e em dois grupos, os comuns, para todas as disciplinas, e os específicos, para a disciplina de Ciências, foram sendo alterados de diferentes maneiras, porém, sempre tendo como base os critérios do PNLD 1999. Esses critérios envolveram correção de conceitos e informações básicas, correção metodológica, estrutura editorial, ilustrações e manual do professor. Já os critérios específicos para a disciplina de Ciências envolveram pertinência metodológica, contribuição para a construção da cidadania, riscos à integridade física dos alunos, adequação dos conteúdos, integração entre temas nos capítulos, atividades que instiguem o raciocínio, aspectos visuais e o manual do professor (BRASIL, 1998b).

A questão da estrutura dos conteúdos nas coleções de Ciências é citada em um dos critérios classificatórios específicos da disciplina que trata da integração entre temas nos capitulos:

Os conteúdos não precisam estar 'encadeados', como se um conceito levasse necessariamente a outro, ou fosse por ele forçosamente precedido. No entanto, o aluno deve perceber a relação existente entre as diferentes partes de um fenômeno natural, incentivando-se a análise de um mesmo fenômeno sob o enfoque de diferentes ciências (aspectos físicos, químicos, biológicos, geológicos, médicos, sanitários, etc.) (BRASIL, 1998b, p. 334). 
A análise de um mesmo fenômeno, considerando os diferentes conhecimentos das Ciências, apresentada no GLD de 1999, aproxima-se das orientações dos documentos oficiais. Porém, no texto introdutório do mesmo GLD é citada uma questão referente à adequação das coleções às propostas curriculares para o ensino de Ciências: "O grande problema com que então nos defrontamos é que muitas publicações distanciam-se das propostas curriculares e dos projetos elaborados por secretarias de educação". (BRASIL, 1998b, p. 9).

Ao analisar livros didáticos para os anos iniciais do Ensino Fundamental, Amaral e Megid Neto (1997) constataram que é esperado que os autores de livros didáticos e as editoras levem em consideração as bases e diretrizes dos documentos oficiais ao elaborarem e divulgarem suas obras, pois, as propostas curriculares se apoiam nos documentos e isso é o que menos tem ocorrido com as coleções analisadas. No nosso estudo, também observamos a não correspondência dos livros didáticos com as recomendações contidas nos documentos oficiais.

As resenhas do GLD 1999 não apresentam um padrão para a organização dos conteúdos nos livros didáticos. Em alguns casos, apenas se registra que a coleção apresenta os conteúdos tradicionais para cada ano da escolaridade, ou que o conjunto de temas é convencional no ensino de Ciências.

Em um dos volumes da $8^{\text {a }}$ série (atualmente $9^{\circ}$ ano), na resenha é citado que a obra "trata de conteúdos de Química e Física de maneira bastante abrangente, lidando com assuntos que tradicionalmente são abordados nesta série e no Ensino Médio" (BRASIL, 1998b, p. 383). Após essa afirmação, não há, na resenha, qualquer comentário explorando quais as implicações de se abordar os assuntos referentes ao Ensino Médio já no Ensino Fundamental. Consideramos que essa antecipação pode fazer com que os alunos percam o interesse pelas disciplinas de Química e de Física, uma vez que serão vistas na etapa seguinte da escolarização. Muitos podem considerá-las difíceis, principalmente pela forma tradicional como são abordados seus conteúdos, criando, assim, uma barreira para a aprendizagem. $\mathrm{Na}$ resenha não há orientações para discutir esses conteúdos.

Segundo Milaré e Alves Filho (2010), dividir o programa escolar do $9^{\circ}$ ano entre Química e Física vem do período do Estado Novo, 1937 a 1945, quando a disciplina de Ciências passou a ser obrigatória para as terceiras e quartas séries do ensino ginasial (hoje $8^{\circ}$ e $9^{\circ}$ anos do Ensino Fundamental), assim as noções de Química e Física ficaram para os últimos anos. Assim,

Quando o Ensino de Ciências passou a permear as demais séries do correspondente ao ensino fundamental atual, estes conteúdos foram distribuídos entre elas: Água, Ar e Solo para o sexto ano; Botânica e Zoologia para o sétimo ano; Corpo Humano para o oitavo ano e, finalmente, Química e Física para o nono ano. (MILARÉ; ALVES FILHO, 2010, p. 103).

Prosseguindo a análise do GLD 1999, em relação ao volume da $5^{\text {a }}$ série (atualmente $6^{\circ}$ ano), o único da coleção aprovada que possui uma estrutura diferenciada dos conteúdos, a resenha chama a atenção afirmando que "uma qualidade notável da obra é a apresentação do conteúdo evitando a tradicional divisão entre água, ar e solo" (BRASIL, 1998b, p. 347). Salientar essa característica do livro pode ajudar o professor a analisar, refletir e lançar um olhar diferenciado não somente para os demais volumes 
dessa coleção, mas também para os de outras coleções.

A partir do PNLD 2002, o grupo de avaliadores passou a ser composto apenas por professores vinculados às universidades, sendo a avaliação de Ciências, de 2002 até 2011, realizada por pesquisadores convidados. Em 2002, foram 33 avaliadores, sendo sete deles mantidos do PNLD 1999. A coordenação geral continuou com o mesmo professor do processo anterior e inserido um coordenador de área.

Nessa avaliação, foram criados mais três critérios eliminatórios comuns: 1) inscrição de mais de uma versão ou variante de uma obra; 2) presença de erros de impressão e de revisão; e 3) inadequada reformulação pedagógica de obras excluídas no PNLD/1999 (BRASIL, 2001). Os critérios específicos para a disciplina de Ciências permaneceram os mesmos, envolvendo correção, adequação e segurança da integridade física dos alunos.

No GLD desse PNLD, a organização dos conteúdos nos livros didáticos era bastante ressaltada, sendo a primeira informação a constar nas resenhas, além de existirem nos textos. Por exemplo, ao tratarem de uma das obras que tem apresentação tradicional dos conteúdos, os avaliadores afirmam que:

[...] a metodologia sugerida ao professor é, portanto, adequada e coerente com a proposta da obra, contribuindo para uma prática pedagógica de qualidade. O conteúdo, porém, é abordado de forma a priorizar a segmentação dos assuntos em cada série e alguns conceitos são apresentados de maneira imprecisa. (BRASIL, 2001, p. 251).

Nos textos introdutórios do GLD 2002, há uma observação chamando a atenção dos professores com relação à organização dos conteúdos:

[...] foram destacados nas resenhas a distribuição dos temas na coleção e os conteúdos trabalhados especificamente em cada volume. Existem coleções que mantiveram a tradicional divisão entre as séries, apresentando conteúdos referentes a 'Ambiente' na $5^{\text {a }}$ série, 'Seres Vivos' na $6^{a}$ série, 'Corpo Humano' na $7^{a}$ série e 'Física e Química' na $8^{\circ}$ série. No entanto, essa rigidez da divisão dos conteúdos aparece flexibilizada em uma das coleções aprovadas. Sem pretender rotular essa segmentação como intrinsecamente positiva ou negativa, há de se ponderar que a divisão disciplinar ao longo das séries induz o professor a analisar os fenômenos naturais a partir de óticas de disciplinas específicas, perdendo de vista compreensões mais amplas que poderiam ser conseguidas a partir da confluência de diferentes disciplinas. Embora, a princípio, possa ser considerado pedagogicamente positivo estudar detidamente um fenômeno a partir de um de seus aspectos (botânico, zoológico, físico, químico), deve-se admitir que abordagens integradas sejam também importantes, em especial em séries mais avançadas. (BRASIL, 2001, p. 220-221, grifos do autor).

No PNLD 2005 a avaliação das coleções foi realizada por 50 pessoas, sendo que nove delas estavam na equipe de 2002 e apenas duas, na equipe de 1999, a coordenação geral e a coordenação de área continuaram as mesmas.

Fazendo uma comparação entre o PNLD 2002 e o PNLD 2005, observase que a análise da estrutura dos conteúdos nas coleções foi menos citada, nos textos introdutórios, nas resenhas e nos critérios de avaliação.

Na ficha de avaliação do PNLD 2005, permanece a estrutura dos conteúdos 
inserida nos critérios classificatórios específicos da área de Ciências, dentro da seção intitulada Os temas propostos, referindo-se aos diferentes capítulos do livro didático. Nessa ficha encontra-se ainda como critério, se os livros "sugerem diferentes análises e perspectivas para os mesmos fenômenos, de forma a desenvolver a curiosidade e o espírito crítico" (BRASIL, 2004, p. 87). Essa mesma abordagem aparece também em outro tópico, denominado características gerais da coleção: "Evita apresentar conteúdos muito distintos nos livros das quatro séries. [...] Apresenta articulação entre as diferentes áreas da Ciência em uma mesma série e ao longo da coleção.” (BRASIL, 2004, p. 90).

Entre os doze critérios eliminatórios para Ciências, nenhum deles trata diretamente da questão da fragmentação dos conteúdos, apenas deixa claro que nenhuma das áreas deve ser suprimida:

Proporciona a iniciação a diversas áreas do conhecimento científico, abrangendo a diversidade de áreas que compõem a disciplina Ciências - zoologia, botânica, ecologia, noções de corpo humano e higiene, física, astronomia e química -, sem suprimir arbitrariamente uma ou mais dessas áreas. (BRASIL, 2004, p. 82).

No texto introdutório do GLD 2005, esse aspecto também é apresentado de forma direta: "A partir das resenhas também será fácil identificar livros nos quais os assuntos são abordados de maneira tradicional ao longo das quatro séries" (BRASIL, 2004, p. 6). Além disso, no texto há um alerta para os professores:

Alguns livros podem, inclusive, não ter aparência tradicional, mas a conhecida divisão de conteúdos ao longo das séries foi mantida, sedimentando a tradicional abordagem que tem no ambiente, nos seres vivos, no corpo humano e na física e química as ênfases de abordagem ao longo das quatro séries. (BRASIL, 2004, p. 6).

A divisão de conteúdos, nesse caso, é feita por unidades de trabalho, sendo que em cada volume do livro didático uma unidade trata de ambiente, outra de seres vivos, outra de corpo humano e outras duas de física e química. Deste modo, mesmo que cada ano apresente todas as áreas que compõem as Ciências, elas são trabalhadas sem conexões entre elas e de forma fragmentada.

No PNLD 2008, houve grande alteração na equipe de avaliadores de Ciências: houve mudança na coordenação técnica e na coordenação de área. A equipe de avaliadores passou a ser montada a partir de convênio do MEC com a USP e foi composta por 47 pessoas, sendo que duas dessas participaram do PNLD 2005. Outra alteração refere-se à presença, na equipe de avaliadores, de professores que atuavam em diferentes níveis de ensino da educação básica, ou exerciam funções em secretarias de ensino, além dos professores do ensino superior, pesquisadores sobre o ensino de ciências e/ou educação científica, envolvidos na formação inicial e continuada de professores (BRASIL, 2007). Conforme consta no texto do GLD, o objetivo foi garantir maior representatividade ao processo de avaliação.

Os critérios eliminatórios e classificatórios das coleções foram discutidos por essa equipe para nortear a análise dos LDs, considerando os aspectos presentes no Edital de convocação de inscrição do PNLD/2008 elaborado pelo MEC 
(BRASIL, 2007). A ficha de avaliação com os critérios descritos não é apresentada como no GLD de 2005, apenas consta no texto do próprio GLD que ela foi organizada em torno de seis categorias de análise referentes ao edital para o PNLD 2008: conhecimentos e conceitos; pesquisa, experimentação e prática; ilustrações, diagramas e figuras; cidadania e ética; proposta pedagógica; manual do professor. A principal alteração foi a presença de um maior número de critérios referentes à experimentação, pesquisa e prática.

$\mathrm{Na}$ ficha de avaliação, quanto ao aspecto da fragmentação dos conhecimentos, no critério Conbecimentos e Conceitos, consta a seguinte observação para análise: "A proposta do livro constitui uma iniciação equilibrada às diferentes áreas do conhecimento científico?” (BRASIL, 2007, p. 101). Contudo, esse critério contradiz o que é encontrado no texto introdutório do mesmo GLD, quando da explicação sobre o modo como ocorreu a avaliação das coleções:

[...] na sequência, cada coleção foi analisada por dois avaliadores de áreas diferentes, sendo que, fundamentalmente, um deles era biólogo de formação, uma vez que a maior parte dos conteúdos no ensino de Ciências de $5^{a}$ a $8^{a}$ séries é desta área de conhecimento. A análise centrou-se em aspectos científicos, metodológicos, pedagógicos, éticos e estéticos definidos de acordo com os novos pressupostos para o ensino de Ciências, configurados pela pesquisa na área e pelas diretrizes curriculares atuais (BRASIL, 2007, p. 11).

Se a maioria das obras apresenta conhecimentos biológicos que prevalecem sobre os demais as coleções não poderiam ser aprovadas, pois um dos critérios de avaliação pede, explicitamente, que o livro se constitua em "uma iniciação equilibrada das diferentes áreas do conhecimento científico” (BRASIL, 2007, p. 101).

Quanto ao Manual do professor, um dos questionamentos para a avaliação é: "O Manual do Professor explica devidamente a estrutura de conteúdos adotada na obra, justificando mudanças em programas tradicionalmente trabalhados, indicando uma bibliografia que permita complementar o conteúdo abordado?” (BRASIL, 2007, p. 105).

Nos textos das resenhas, não se encontra a maneira convencional de como são apresentados os conteúdos. Em apenas uma das resenhas, há referência a esse aspecto: "A estrutura dos conteúdos da coleção é convencional, variando no aprofundamento com que trata os diferentes temas" (BRASIL, 2007, p. 40).

A coleção com uma organização diferenciada dos conteúdos, de maneira a integrar os conhecimentos que compõem a disciplina de Ciências, aprovado no PNLD de 2008, em sua resenha consta:

A maioria dos conteúdos é adequada à faixa etária dos alunos e respeita o estágio de desenvolvimento cognitivo dos alunos. [...] $\mathrm{O}$ tratamento dado às diferentes áreas é adequado e inovador em muitos aspectos, ressaltando-se, como qualidades, o uso da história da ciência, a relação entre os conteúdos e o cotidiano dos alunos, a presença de numerosas propostas de atividades práticas, o incentivo à pesquisa e a abordagem interdisciplinar (BRASIL, 2007, p. 56).

No entanto, na resenha não é explorada a abordagem de conteúdos de maneira diferenciada do convencional, como nos GLDs anteriores, e também 
não enaltece essa característica como algo que se aproxima das orientações que constam nos documentos oficiais.

$\mathrm{Na}$ edição de 2011, foram 28 avaliadores, sendo que, destes, oito participaram do PNLD 2008. O coordenador técnico continua o mesmo professor do processo anteriror, mudando apenas o coordenador de área. O texto inicial do GLD incentiva a experimentação e a investigação no ensino de Ciências, ainda com maior destaque do que no PNLD 2008.

Para o PNLD 2011, as coleções didáticas foram analisadas com base em cinco categorias: abordagem do conteúdo; abordagem pedagógica; atividades experimentais e de investigação científica; manual do professor; e projeto gráfico. A ficha de avaliação, por sua vez, baseou-se em seis categorias de análise: cumprimento das normas oficiais; ética e cidadania; proposta pedagógica; conteúdos; manual do professor; projeto gráfico (BRASIL, 2010b).

A discussão da organização dos conteúdos nos livros didáticos é abandonada no GLD 2011, e a experimentação ganha maior destaque ainda do que no PNLD 2008. A abordagem tradicional dos conteúdos nos volumes é citada nas resenhas, mas sem a problematização desse aspecto no ensino de Ciências ou, tendo como referência as orientações dos documentos oficiais. Algumas vezes, a presença da fragmentação dos conteúdos nos livros didáticos é até elogiada. Por exemplo, na resenha de uma das coleções há a seguinte afirmação: "um dos pontos fortes da coleção é o fato dela cobrir, com detalhes, todo o conteúdo tradicional de Ciências, do $6^{\circ}$ ano ao $9^{\circ}$ ano" (BRASIL, 2010b, p. 30). Em outra resenha, há a seguinte descrição: "Os conteúdos da coleção são estruturados em uma forma convencional, com abordagem equilibrada das áreas do conhecimento científico e, eventualmente, com bastante detalhamento" (BRASIL, 2010b, p. 76).

Essas afirmações podem levar a uma concepção do ensino de Ciências de que existe um "conteúdo tradicional de Ciências, do $6^{\circ}$ ano ao $9^{\circ}$ ano" (BRASIL, 2010b, p. 30), que deve estar presente em todas as coleções de livros didáticos, ou ainda, que uma estrutura convencional, fragmentando os conhecimentos, possa permitir uma "abordagem equilibrada das áreas do conhecimento científico" (BRASIL, 2010b, p. 76).

No texto de várias resenhas, são apontadas as conformidades das coleções com os PCNs, por exemplo, o modo de organização da coleção e o cotidiano do aluno, mas silencia sobre orientações para a organização dos conteúdos. Na resenha da única coleção aprovada que apresenta conteúdos organizados de maneira diferente da tradicional, é ressaltado no texto:

[...] trata-se de uma coleção muito bem elaborada, a partir de uma proposta pedagógica claramente apresentada e desenvolvida. Cabe destaque à: organização dos conteúdos valorizando a interdisciplinaridade e a contextualização a partir de ideias-chave cuidadosamente selecionadas (BRASIL, 2010b, p. 82).

Consta, ainda, nessa resenha, que a organização dos conteúdos promove maior comunicação entre os saberes das várias disciplinas que compõem a área de Ciências e que o manual do professor é muito bem estruturado e possibilita um suporte para o professor realizar o trabalho proposto. Essas afirmações, contidas na resenha permitem inferir que a contextualização e a articulação entre os saberes das 
várias disciplinas que compõem a área de Ciências, são consideradas pontos positivos.

A partir do PNLD de 2014, conteúdos multimídia passaram a ser inscritos e avaliados e, para tanto, três avaliadores ficaram responsáveis somente por essa análise. Para os livros foram designados 32 avaliadores, sendo que seis deles participaram do PNLD 2011. A coordenação técnica não foi alterada, mas houve mudança na coordenação de área.

O ensino investigativo e experimental de Ciências continuou sendo considerado nessa edição. O texto introdutório do GLD afirma que "o foco para uma boa escolha do livro de ciências está na questão metodológica, isto é, se a proposta pedagógica contempla um ensino investigativo e experimental." (BRASIL, 2013b, p. 7).

No PNLD de 2014, as categorias de análise das coleções não são mais utilizadas e voltam a configurar os critérios eliminatórios e classificatórios, de maneira mais específica, com apresentação mais organizada e em seções separadas do restante dos textos do GLD.

Um dos critérios eliminatórios específicos de Ciências refere-se à “articulação dos conteúdos de Ciências com outros campos disciplinares" (BRASIL, 2013b, p. 10), porém, nenhum desses critérios apresenta sugestões ou orientações a respeito da conexão e articulação dos conteúdos entre as áreas, que compõem a própria disciplina de Ciências. Apenas um deles está relacionado com o fato de que "deve ocorrer iniciação às diferentes áreas do conhecimento científico, assegurando a abordagem de aspectos centrais em física, astronomia, química, geociências, ecologia, biologia e saúde" (BRASIL, 2013b, p. 10), como constava no PNLD de 2011.

A questão da organização dos conteúdos é citada em uma das resenhas de coleção com organização tradicional dos conteúdos. O parecer diz: "sugerese ao professor atentar para estabelecer interações entre os conteúdos de Física, Química e Biologia e, na medida do possível, com outras áreas do conhecimento." (BRASIL, 2013b, p. 19). Nas resenhas de outras coleções, há um silêncio sobre a organização dos conteúdos.

Nas resenhas de duas outras coleções, encontra-se a afirmação que os conteúdos são organizados de maneira tradicional e que, em alguns momentos, a linguagem se apresenta em um patamar acima do entendimento esperado para os alunos dos anos finais do Ensino Fundamental, principalmente quanto aos conteúdos de Química e Física do $9^{\circ}$ ano. Isso indica, como já ocorreu em análise anterior, que os conteúdos adiantam linguagens e situações que seriam abordadas no Ensino Médio, dentro das disciplinas de Química e de Física.

Essa configuração dos livros didáticos contribui para que a modificação do programa escolar seja a última opção adotada, para amenizar obstáculos encontrados por alunos e professores no Ensino de Ciências, principalmente no que se refere ao $9^{\circ}$ ano. $\mathrm{Na}$ verdade, devido ao padrão seguido nos livros didáticos e a sua não problematização nos GLDs e avaliações do PNLD, muitos professores podem ter o entendimento de que é indispensável preparar os alunos do $9^{\circ}$ ano para o estudo de Química e de Física no Ensino Médio (MILARÉ; ALVES FILHO, 2010), de modo que esses conteúdos permaneçam sendo trabalhados de maneira isolada no $9^{\circ}$ ano.

Nas resenhas das coleções com abordagem diferenciada dos conteúdos, essa característica é ressaltada de forma positiva: "Os conteúdos são apresentados 
de forma plenamente articulada e correta. Em todos os volumes estão presentes conceitos de Biologia, Química, Física, Astronomia articulados entre si e com outras áreas, como Geografia, Matemática e História” (BRASIL, 2013b, p. 23). É ressaltado, ainda, que: "A coleção caracteriza-se por apresentar uma proposta inovadora, com elogiável organização e tratamento dos conteúdos quanto aos aspectos pedagógicos" (BRASIL, 2013b, p. 25).

\section{DISCUSSÃO DOS DADOS}

Os resultados da pesquisa nos levam à seguinte problematização: por que o PNLD não insere, como um critério de grande relevância na avaliação, a análise referente à organização dos conteúdos nos livros didáticos de Ciências, considerando esse um elemento importante para se aproximar do que se espera do Ensino de Ciências na atualidade? Os GLDs poderiam estar organizados segundo uma estrutura que mantivesse, em todas as resenhas, uma mesma abordagem sequencial dos critérios de avaliação, não suprimindo informações ou critérios para cada uma das coleções avaliadas.

A fragmentação dos conteúdos nos livros didáticos, que se expande para os currículos de Ciências dos anos finais do Ensino Fundamental, é uma característica estabelecida historicamente. Esse tratamento disciplinar da Ciência contraria as propostas dos documentos oficiais nacionais - como a Lei de Diretrizes e Bases da Educação Nacional, as Diretrizes e Propostas Curriculares e de pesquisas em ensino desenvolvidas por diferentes pesquisadores nas últimas décadas (MILARÉ; ALVES FILHO, 2010).

O Governo Federal, por meio de diferentes equipes do MEC, publicou e divulgou amplamente os documentos e pareceres oficiais para o Ensino de Ciências. Esse mesmo órgão governamental realiza a avaliação das coleções de livros didáticos por meio do PNLD, cujo objetivo está direcionado para orientar o professor na análise e escolha do livro didático a ser utilizado em seu trabalho. Para isso, é publicado o GLD, com elementos que "fomentam a decisão sobre quais são os livros didáticos mais adequados para o trabalho docente, tanto em relação aos conteúdos propostos, quanto aos aspectos teórico-metodológicos e ao manual do professor". (GUIMARÃES, 2011, p. 18). Esperava-se, desse modo, que as orientações dos dois processos fossem compatíveis, porém, pela análise realizada observou-se que tal fato não ocorre para a disciplina de Ciências nos anos finais do Ensino Fundamental.

Assim, tendo como foco a fragmentação dos conteúdos nos livros didáticos de Ciências, identificou-se nos processos do PNLD uma não linearidade tanto nas fichas de avaliação, quanto nos textos das resenhas dos GLDs. Observou-se, ainda, que quando a abordagem não fragmentada dos conteúdos está presente na coleção, tal fato é elogiado nas resenhas. Por outro lado, nas coleções tradicionais, em geral, não é feita qualquer observação sobre a organização dos conteúdos. Assim, o critério referente à fragmentação dos conteúdos esteve presente nas avaliações realizadas nos PNLDs de 1999, 2002 e 2005 e, a partir do PNLD 2008, vem perdendo a ênfase.

Com relação aos critérios de avaliação do PNLD no período analisado, identificamos que, em sua maioria, eles não se referem às especificidades do ensino de Ciências, mas sim consideram aspectos mais gerais que poderiam ser utilizados para 
outras áreas do conhecimento, como: descritores de atividades, aspectos físicos do livro, manual do professor, qualidade gráfica. Essa tendência também foi identificada na pesquisa de Leão e Megid Neto (2006), no PNLD dos anos iniciais, em que as questões mais específicas e fundamentais para o ensino de Ciências foram deixadas de lado, privilegiando critérios classificatórios comuns às demais áreas de ensino escolar.

O livro didático, além de ser utilizado pelos alunos, é considerado como um complemento para a prática pedagógica do professor. Assim sendo, o PNLD deveria disponibilizar coleções didáticas atualizadas e com tipos de organização de conteúdos que permitissem ao professor escolher a coleção que seja mais adequada aos seus alunos. Dessa forma, ampliaria-se a possibilidade de contemplar distintas realidades educacionais que existem em todo o território nacional, já que o Governo Federal tem investido milhões de reais na compra de livros didáticos. Além disso, a prática da leitura e discussão dos GLDs pelo professor em conjunto com seus pares, no momento da escolha do livro didático poderia ser uma importante contribuição para desenvolver e ampliar o olhar crítico dos professores sobre o material que certamente estará presente em suas aulas.

Esse olhar crítico se faz necessário, pois a evolução histórica dos objetivos do ensino de Ciências se situa basicamente na preocupação constante com a atualização dos conteúdos em relação ao progresso da própria Ciência. Porém, com a análise e discussão da concepção de ensino de Ciências e das políticas educacionais atuais não ocorre o mesmo, sendo que essas preocupações se mostram necessárias para que ações padronizadas não continuem presentes embasando ideias já superadas no Ensino de Ciências (KRASILCHIK, 1998).

Além disso, com uma maior variedade de opções de livros didáticos, com organização e estrutura diferenciadas, disponibilizados pelo PNLD, maiores serão as possibilidades de os professores questionarem a estrutura dos livros. Dessa forma, é possível reconhecer que não há um único padrão estabelecido para que todos sigam a mesma organização pedagógica ou de conteúdos, mas possam renovar e estabelecer novas possibilidades para o ensino de Ciências.

\section{CONSIDERACְ̃̃ES FINAIS}

A avaliação e oferta dos livros didáticos pelo PNLD são legítimas e esse procedimento fez com que muito se avançasse em sua qualidade, como impressão, ilustração, redução significativa de erros conceituais, preconceitos e estereótipos. Contudo, incentivar os professores a questionarem o que é apresentado nos GLDs e nos critérios de análise, além de extremamente salutar, poderia contribuir para que alterações significativas se processassem nos critérios de avaliação do PNLD.

O livro didático é apenas uma das peças no desenvolvimento do trabalho em sala de aula e somente cada professor pode avaliar de que maneira irá planejar e estruturar os conhecimentos, tendo por referência seus alunos e a realidade em que vivem. Isso denota a necessidade de aprofundamentos nas reflexões sobre os livros didáticos, a estruturação dos GLDs e o processo de avaliação do PNLD.

Diante do que foi apresentado neste texto, lança-se a questão: por que o MEC não realiza novos seminários e debates, semelhantes aos realizados para a primeira edição, em 1999, para que outros aspectos e critérios para avaliação dos 
livros didáticos de Ciências sejam incorporados e/ou modificados?

Por ser o maior comprador de obras didáticas no mercado brasileiro, o MEC pode alterar suas exigências referentes ao que espera para o Ensino de Ciências, levando o mercado editorial a realizar alterações em sua produção, pois, "uma vez omitidos nas avaliações, os fundamentos do ensino de Ciências deixam de orientar as reformulações das coleções didáticas existente, bem como das novas produções”. (AMARAL, 2006, p. 97).

A presença de pelo menos uma coleção com organização de conteúdos diferenciada em cada processo do PNLD - Ciências demonstra que algumas editoras se arriscam mercadologicamente, desenvolvendo coleções com outras perspectivas. E por qual motivo o fazem? Acredita-se que, talvez, pelo fato de essas coleções aparecerem bem avaliadas nos quadros dos GLDs ou para que públicos diferenciados de professores e até mesmo de avaliadores sejam contemplados e pelo menos uma das coleções que a editora inscreve seja aprovada no PNLD, garantindo espaço no mercado.

Considera-se importante refletir sobre o papel do GLD para os docentes, a sua impressão sobre o PNLD e como essa discussão está presente nas licenciaturas e na formação continuada dos professores. Além disso, seria necessária uma maior clareza e uniformidade nas resenhas com relação à análise de cada característica da coleção e dos critérios, para que informações importantes não fossem omitidas de uma coleção para outra.

\section{REFERÊNCIAS}

AMARAL, I. A. do. Os fundamentos do ensino de Ciências e o livro didático. In: FRACALANZA, H.; MEGID NETO, J. (Orgs.). O livro didático de Ciências no Brasil. Campinas: Editora Komedi, 2006. ; MEGID NETO, J. Qualidade do livro didático de Ciências: o que define e quem define? Ciência \& Ensino, Campinas, n.2, jun.1997.

BARDIN, L. Análise de conteúdo. Lisboa, Portugal; Edições 70, LDA, 2009.

BRASIL. Lei de Diretrizes e Bases da Educação Nacional. Brasília: 1996.

Parâmetros Curriculares Nacionais: Ciências Naturais / Secretaria de Educação Fundamental. Brasília: MEC/SEF, 1998a.

Guia de livros didáticos: PNLD 1999 - 5a a $8^{a}$ séries. Brasília: Ministério da Educação e do Desporto, 1998b.

Guia de livros didáticos: PNLD $2002-5^{a}$ a $8^{a}$ séries. Brasília: Ministério da Educação e do Desporto, 2001.

Guia de livros didáticos: PNLD 2005 - Ciências. Brasília: Ministério da Educação, Secretaria da Educação Básica, 2004.

Guia de livros didáticos: PNLD 2008 - Ciências. Brasília: Ministério da Educação, Secretaria da Educação Básica, 2007.

Diretrizes Curriculares Nacionais Gerais da Educação Básica / Secretaria de Educação Fundamental. Brasília: MEC/SEB/DICEI, 2010a.

Guia de livros didáticos: PNLD 2011 - Ciências. Brasília: Ministério da Educação, Secretaria da Educação Básica, 2010b.

Histórico. Ministério da Educação - MEC. Programa Nacional do Livro Didático PNLD. Disponível em: <http://www.mec.gov.br>. Acesso em: 01 jul. 2013a. 
Guia de livros didáticos: PNLD 2014 - Ciências. Brasília: Ministério da Educação,

Secretaria da Educação Básica, 2013b.

Fundo Nacional de Desenvolvimento da Educação. Programa Nacional do Livro Didático - Anos finais do Ensino Fundamental. Disponível em: < http://www.fnde.gov.br/ programas/livro-didatico>. Acesso em: 10 jan. 2014.

FERREIRA, A. de M.; SOARES, C. A. A. A. Aracnídeos Peçonhentos: análise das informações nos livros didáticos de Ciências. Ciência e Educação, v. 14, n. 2, p. 307-314, 2008.

FRACALANZA, H.; MEGID NETO, J. (Orgs.). O livro didático de Ciências no Brasil. Campinas: Editora Komedi, 2006.

GOMES, M. M.; SELLES, S. E.; LOPES, A. C. Currículo de Ciências: estabilidade e mudança em livros didáticos. Educação em Pesquisa, São Paulo, v. 39, n. 2, p. 477-492, 2013.

GRAMOWSKI, V. B. O livro didático de Ciências: a persistência da fragmentação dos conteúdos. 2014. 208 f. Dissertação (Mestrado em Educação Científica e Tecnológica) - Programa de Pós-graduação em Educação Científica e Tecnológica, Universidade Federal de Santa Catarina, Florianópolis. 2014.

GUIMARÃES, F. M. Como os professores de $6^{\circ}$ ao $9^{\circ}$ anos usam os livros didáticos de Ciências, 2011. Dissertação de mestrado (Faculdade de Educação) - Universidade de Campinas, Campinas, SP, 2011.

HÖFLING, E. M. Notas para discussão quanto à implementação de programas de governo: em foco o Programa Nacional do Livro Didático. Educação e Sociedade, Campinas, v. 21, n. 70, p. 159-170, 2000.

KRASILCHIK, M. Prática de Ensino de Biologia. São Paulo: Harbra, 1998.

LEÃO, F. de B. F.; MEGID NETO, J. Avaliações Oficiais Sobre o Livro Didático de Ciências. In: FRACALANZA, H. e MEGID NETO, J. (Orgs.). O livro didático de Ciências no Brasil. Campinas: Editora Komedi, p. 35-80, 2006.

MACEDO, E. F. As ciências no ensino fundamental: Perspectivas atuais. In: III Encontro Nacional de Pesquisa em Educação em Ciências - III ENPEC, 2001, Atibaia - SP. Atas do III Enpec, n. 3, Atibaia, 2001.

MAGALHÃES JÚNIOR, C. A. de O.; PIETROCOLA, M. Análises de propostas para a formação de professores de Ciências do Ensino Fundamental. Alexandria, v. 3, n. 2, p. 31-58, 2010.

MILARÉ, T.; ALVES FILHO, J. de P. Ciências no nono ano do Ensino Fundamental: da disciplinaridade à Alfabetização Científica e Tecnológica. Ensaio, v. 12, n. 02, p. 101-120, 2010.

OLIVEIRA, J. B. A. O Livro Didático - Os livros descartáveis: exigência pedagógica ou apenas um bom negócio? Cadernos de Pesquisa - Revista de Estudos e Pesquisas em Educação, n. 44, p. 90-94, 1983.

\section{NOTAS}

${ }^{1}$ Políticas públicas de Estado são aquelas que ultrapassam o período de um governo, se consolidando dentro da sociedade. Já as políticas públicas de governo são instituídas por um governo durante o seu período de vigência, sendo abandonada ao trocar de governante.

${ }^{2}$ Os livros didáticos descartáveis foram padrão típico disponível no país nas décadas de 1970 e 1980 , principalmente no que, atualmente, corresponde aos anos iniciais do Ensino Fundamental. Nesses materiais didáticos, os alunos podiam escrever as respostas, o que tornava inviável sua reutilização no ano posterior por outro aluno (OLIVEIRA, 1983). Assim, era alvo de inúmeras críticas, como a citada por Oliveira (1983, p. 90): “As implicações da utilização generalizada de livros descartáveis num país pobre e historicamente deficiente no seu sistema educacional pode estar contribuindo para agravar ainda mais a falta de disponibilidade de livros e materiais didáticos para alunos mais carentes". 
${ }^{3}$ Os PCNs, embora considerados pelo Conselho Nacional de Educação (CNE) como guias curriculares não obrigatórios e não passíveis de subsidiar processos de avaliação nacional, são referência na maioria das escolas do país, devido ao esforço do Ministério da Educação (MEC) na sua divulgação (MACEDO, 2001).

${ }^{4}$ Neste trabalho, o termo fragmentação está sendo compreendido como a abordagem de conteúdos de Biologia, Química, Física e Geociências que compõem a disciplina de Ciências de maneira isolada, dentro de cada um dos anos correspondentes aos anos finais do Ensino Fundamental. Dessa maneira, não ocorre a articulação desses conhecimentos para a análise dos diferentes fenômenos naturais que são discutidos nessa disciplina nesse nível de ensino. Gomes, Selles e Lopes (2013) identificam a fragmentação dos conteúdos, como padrões estáveis nas temáticas dos quatro anos finais do ensino fundamental, respectivamente: ar, água e solo; seres vivos; anatomia e fisiologia humana; física e química, o que limita a perspectiva para um ensino de Ciências dinâmico e articulado.

${ }^{5}$ Os critérios de avaliação de cada um dos processos do PNLD estão disponíveis no seu respectivo GLD e podem ser acessados no site do FNDE: http://www.fnde.gov.br/programas/livro-didatico/ guias-do-pnld. Não são aqui apresentados por questão de espaço.

\section{Informações sobre a participação dos autores na elaboração deste artigo:}

Primeira autora: elaborações teóricas e metodológicas relacionadas à dissertação de mestrado.

Coautora 1: orientadora da dissertação de mestrado, coordenadora e colaboradora na elaboração do artigo. Coautora 2: coorientadora da dissertação de mestrado e colaboradora na elaboração do artigo.

Submetido em 30/11/2015

Aprovado em 18/04/2017

\section{Contato:}

Vilmarise Bobato Gramowski

Universidade Federal de Santa Catarina

Centro de Ciências Físicas e Matemáticas

Programa de Pós-Graduação em Educação Científica e Tecnológica

Blocos Modulados - Corredor B, Sala 1

Campus Universitário Trindade

CEP: 88040-900 Florianópolis, SC - Brasil. 